\title{
Living with multiple chronic conditions: how exercise helps me self-manage my conditions
}

\author{
Gregers Aagaard
}

\begin{abstract}
My name is Gregers, I am 72 years old and I live with several chronic conditions: osteoarthritis in the knees and hips, hypertension, gout, atrial tachycardia, low back pain, asthma, rapid eye movement sleep behaviour disorder, obstructive sleep apnoea, central sleep apnoea and periodic limb movement disorder.
\end{abstract}

My conditions have a great impact on my daily life, both physically and mentally. In particular, the osteoarthritis in my knees and hips and my low back pain are the two most painful and disabling conditions for me. My sleep disturbance conditions are the ones that affect my psychosocial health most though, as the thought of possibly developing diseases like Parkinson's or dementia as sequelae to these conditions, ${ }^{1}$ is depressing to me.

With this article, I would like to share my story and the strategies I have to selfmanage my chronic conditions.

\section{MY STORY OF LIVING WITH MULTIPLE CHRONIC CONDITIONS}

Living with multiple chronic conditions means many visits to my general practitioner and specialists, at least one for each single disorder. In my experience, the doctors I have met were very informative and provided much information about my ailments. The decisions on the treatments I need are often made for me by them.

The first major treatment I received, 15 years ago, was a total knee replacement of both of my knees. The surgery helped me to get better, the pain lessened considerably, and I was able to do more with less difficulty (such as cross-country skiing and hillwalking). I was not close to the level of function from my younger years, but allin-all, it was a major improvement of the quality of my life.

Over the years, I have undergone numerous other treatments for my conditions, including five direct current cardioversions to restore the normal rhythm in my heart, and an ablation to stop the onset of atrial tachycardia.

Department of Sports Science and Clinical

Biomechanics, University of Southern Denmark, Odense, Syddanmark, Denmark
My obstructive sleep apnoea is a potentially life-threatening condition, which can be treated by using a CPAP machine. ${ }^{2}$ The Danish healthcare system has provided me with one which I use every night with positive effects. Recently I also had a consultation with a neurologist about a subtly increasing loss of cognitive skills I have felt over the last couple of years and which I am concerned about.

All of the above is accompanied by consuming a lot of medicine, at least one pill for each condition. Apart from the hassle of taking a total of 14 pills during the day, the cost of medicine can be considerable. Luckily, the Danish healthcare system subsidises my medicine costs if they exceed a certain limit, but it still is a significant cost.

\section{THE IMPACT ON MY DAILY ACTIVITIES}

Today, I can only walk on a flat terrain over a distance of about 1 kilometre, preferably with a walking stick as an aid. Many daily activities, such as gardening, cleaning and lifting or playing with my grandchildren, are difficult or impossible, let alone the sporting activities I enjoyed earlier in life. Being a physical education teacher, I have always been very physically active, but during the last 15 years, I have gradually given up my sporting pursuits. First, it was judo, then basketball, badminton and alpine skiing, and latterly mountain hiking, cross-country skiing, running and kayaking (an activity which I have enjoyed a lot). Finally, I sadly had to give up scuba diving 3 years ago due to my asthma.

\section{WHAT HELPS ME SELF-MANAGE MY CONDITIONS}

My strategy is exercise. I use the Good Life with Osteoarthritis in Denmark programme ${ }^{3}$ as a model but have increased my number of training days to 3 instead of 2 and I use cable machines instead of exercise bands. I put the workloads to my maximum, and after $25 \mathrm{~min}$, the endorphins kick in and I feel 30 years younger! There may be some payback later, but it is worth it. I feel that through my training I am able to increase my quality of life,

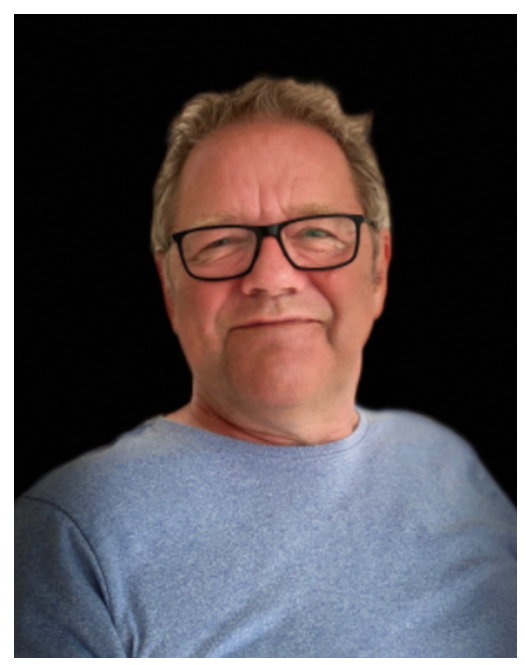

both mentally and functionally. Many everyday tasks become easier, which gives me an increased sense of independence and boosts my confidence. And last but not least, playing with my grandchildren becomes a lot easier.

Luckily, exercise is encouraged for each and every one of my conditions (including dementia) and that is why I decided to serve as a patient partner in the MOBILIZE project. ${ }^{4}$

THREE TIPS FOR OTHER PEOPLE LIVING WITH MULTIPLE CHRONIC CONDITIONS Carpe Diem. There is very little chance that your condition(s) will improve themselves, so there is a great risk that you cannot do tomorrow what you can do today. So, do it today.

Medications. Check your prescription thoroughly with your general practitioners and specialists. Sometimes, there may be the possibility of reducing the number of pills that you take and, sometimes, errors occur.

Exercise! There is a lot of evidence supporting that exercise is good for your health and also for your mood, whatever your conditions are. So, exercise and postpone the inevitable.

Contributors GA is a patient partner in the MOBILIZE project hosted by the University of Southern Denmark. GA has drafted the Patient Voices manuscript and will be the sole author of this work. JRP has assisted in the submission process.

Funding This study was funded by Naestved, Slagelse and Ringsted Hospitals Research Fund; H2O2O European Research Council (801790); The Association of Danish Physiotherapists.

Competing interests None declared.

Patient consent for publication Not required.

Provenance and peer review Not commissioned; internally peer reviewed.

(C) Author(s) (or their employer(s)) 2021. No commercial re-use. See rights and permissions. Published by BMJ. 


\section{Check for updates}

To cite Aagaard G. Br J Sports Med Epub ahead of print: [please include Day Month Year]. doi:10.1136/ bjsports-2021-104382

Accepted 19 August 2021

Br J Sports Med 2021;0:1-2

doi:10.1136/bjsports-2021-104382

\section{REFERENCES}

1 Schenck CH, Boeve BF, Mahowald MW. Delayed emergence of a parkinsonian disorder or dementia in $81 \%$ of older men initially diagnosed with idiopathic rapid eye movement sleep behavior disorder: a 16-year update on a previously reported series. Sleep Med 2013;14:744-8.

2 Wozniak DR, Lasserson TJ, Smith I. Educational, supportive and behavioural interventions to improve usage of continuous positive airway pressure machines in adults with obstructive sleep apnoea. Cochrane Database Syst Rev 2014;8:CD007736.

3 Skou ST, Roos EM. Good Life with osteoArthritis in Denmark (GLA:DTM): evidence-based education and supervised neuromuscular exercise delivered by certified physiotherapists nationwide. BMC Musculoskelet Disord 2017;18:1-13.

4 Mobilize project. Available: https://www.mobilizeproject.dk/?lang=en [Accessed 17 May 2021]. 